\title{
Efficient Protein Digestion at Elevated Temperature in the Presence of SDS and Calcium lons for Membrane Proteomics
}

Jessica Loraine ${ }^{\dagger}$, Ohoud Alhumaidan ${ }^{\dagger} \$ \$$, Andrew R. Bottrill ${ }^{\perp \|}$, Sharad C. Mistry ${ }^{\perp}$, Peter Andrew ${ }^{\dagger, \hbar}$, Galina V. Mukamolova ${ }^{\dagger, *}$ and Obolbek Turapov ${ }^{\dagger, \star *}$

†Department of Infection, Immunity and Inflammation, University of Leicester, Leicester, LE1 9HN, UK

Department of Respiratory Sciences, University of Leicester, Leicester, LE1 9HN, UK

§Department of Clinical Laboratory Sciences, King Saud University. Riyadh, Saudi Arabia

${ }^{\perp}$ Protein Nucleic Acid Laboratory, University of Leicester, Leicester, LE1 7RH, UK, "Current address: Proteomics Research Technology Platform, School of Life Sciences, University of Warwick, CV4 7AL, UK

\section{AUTHOR INFORMATION}

\$These authors contributed equally to this work

\section{Corresponding Author}

*E-mail: ot16@le.ac.uk

\section{ABSTRACT}

Growing significance of membrane proteins inspires continuous development and improvement of methods for robust membrane proteomics. Here, we developed a very simple and efficient method for membrane protein digestion using an ionic detergent sodium dodecyl sulphate (SDS) at high temperature, conditions where trypsin is normally inactivated. Our results suggest that trypsin can be stabilized by a combination of calcium ions and sodium chloride which enables protein digestion at elevated temperature in the presence of strong ionic detergents such as SDS. Finding conditions for stabilisation of trypsin offers novel opportunities for application of detergents for investigation of membrane proteins. 


\section{INTRODUCTION}

Membrane proteins play an essential biological role in all genera of life. These proteins are critical for cell-cell communication, transport of chemicals, sensing environmental changes and pathogenesis. The membrane proteins of microorganisms are in the frontline of the host-parasite/symbiont interactions. ${ }^{1,2}$ Understanding the role and function of these membrane proteins is crucial for environmental and medical biology; however, they are challenging to handle and digest for proteomics analysis. ${ }^{3}$ For analytical purposes membrane proteins are extracted from the membrane and identified using a variety of analytical and biochemical techniques. For the proteomic analysis proteins are digested with a suitable enzyme and generated fragments are analysed by mass spectrometry. 3,4 To achieve efficient digestion, proteins are chemically denatured prior to proteinase digestion. ${ }^{4-7}$ The traditional methods require removal of denaturing agents and may result in loss of valuable samples. ${ }^{7,8}$ Many alternative methods for improvement of protein digestion have been developed including application of high temperature, ${ }^{7}$ microwave irradiation technology, ${ }^{9}$ pressure-assisted treatment, ${ }^{10}$ focused ultrasound technique ${ }^{11}$. However, these techniques have been mainly used for digestion of soluble cytoplasmic proteins, while processing of membrane and cell wall proteins for down-stream analysis remains problematic.

Trypsin is the most popular enzyme used in proteomics because of its exceptional specificity and ability to cleave proteins into the fragments in the ideal range for mass spectrometry. ${ }^{12}$ At the same time, this is a powerful enzyme with a comparatively good stability under various conditions. ${ }^{13}$ Improving stability of the proteolytic enzyme enables exploration of more potent conditions for membrane protein digestion.

Here, we developed a method of stabilisation of trypsin in the presence of strong ionic detergents. We evaluated this method initially for digestion of ovalbumin, which is highly resistant to proteolytic cleavage. Then digestion/identification of membrane proteins from Listeria monocytogenes, a Gram positive pathogen, was performed using this method. Our results suggest that trypsin can be stabilized by $\mathrm{Ca}^{2+}$ ions and used for protein digestion at elevated temperature in the presence of strong ionic detergent, SDS. Formation of calcium dodecyl sulphate precipitates can be prevented by $\mathrm{NaCl}$. Application of this method resulted in higher efficiency of digestion and improved identification of membrane proteins. Our simple and efficient method opens 
novel directions for optimisation of methods for digestion and analysis of membrane proteins.

\section{EXPERIMENTAL SECTION}

\section{Materials and Reagents}

Ovalbumin (A5503-1G), analytical grade Tris- $\mathrm{HCl}, \mathrm{NaCl}, \mathrm{HCl}, \mathrm{CaCl}_{2}, \mathrm{SDS}$, DTT, water and glass beads were purchased from Sigma-Aldrich, UK. Proteomics grade trypsin (\#P1228-1000, $1 \mathrm{mg}$ ) was purchased from BioVision Incorporated. PAGE instruments were from Geneflow (England). Low Protein Binding Collection Tubes (\#90410, Thermo Fisher Scientific) were used in all experiments.

\section{Experimental Procedures.}

Preparation of trypsin. Trypsin was reconstituted in diluted $0.037 \%(\mathrm{w} / \mathrm{v}) \mathrm{HCl}$ solution, $\mathrm{pH} 2.0$ to a final concentration of $1 \mathrm{mg}$ per $\mathrm{mL}$.

Preparation of bacterial culture. L. monocytogenes EGD-e was inoculated into $5 \mathrm{ml}$ of Brain Heart Infusion broth from a frozen stock and incubated overnight at $37^{\circ} \mathrm{C}$ in a shaking incubator. The starter culture $(1 \mathrm{ml})$ was inoculated into $500 \mathrm{~mL} \mathrm{BHI}$ medium and incubated at $37^{\circ} \mathrm{C}$ to $\mathrm{OD}_{600 \mathrm{~nm}} \sim 0.9$. Bacteria were pelleted by centrifugation at $5000 \times \mathrm{g}$ for 20 minutes and used for isolation of membrane fractions.

Isolation of membrane proteins. The membrane fraction was isolated as described before. ${ }^{14,15}$ Briefly, L. monocytogenes cell pellets were washed twice in lysis buffer (Tris $\mathrm{HCl}, 20 \mathrm{mM}, \mathrm{pH} 8.5, \mathrm{NaCl} 150 \mathrm{mM}, \mathrm{MgCl}_{2} 10 \mathrm{mM}$ ) and resuspended in the same buffer containing cOmplete ${ }^{\mathrm{TM}}$ Mini EDTA-free Protease Inhibitor Cocktail (Roche). The cells were lysed in a Minilys Personal Homogenizer (Bertin Instruments) using acidwashed glass beads (150-212 $\mu \mathrm{m}$, Sigma) at maximum amplitude for $45 \mathrm{sec}$. The procedure was repeated 3 times and the cell lysates were centrifuged at $2500 \times \mathrm{g}$ for $15 \mathrm{~min}$. The supernatant was then centrifuged at $27000 \times \mathrm{g}$ for $30 \mathrm{~min}$ (pellet discarded) and at $100000 \times \mathrm{g}$ for $60 \mathrm{~min}$. This pellet was then washed $(100,000 \times \mathrm{g}$ for $60 \mathrm{~min}$ ) once in lysis buffer without magnesium. This was then washed twice in carbonate buffer ( $\mathrm{pH} 10)$ and once in water.

Ovalbumin digestion at elevated temperature (DIET). Ovalbumin was digested without denaturation or alkylation. In each experiment $2.5 \mu \mathrm{g}$ of ovalbumin was used in $15 \mu \mathrm{L}$ of $10 \mathrm{mM}$ Tris $\mathrm{HCl}$ buffer ( $\mathrm{pH}$ as indicated) containing $5 \mathrm{mM}$ dithiothreitol, $0.1 \%(\mathrm{w} / \mathrm{v}) \mathrm{SDS}$ and $200 \mathrm{mM} \mathrm{NaCl}$. Calcium chloride was added to a final 
concentration of $10 \mathrm{mM}$ prior to digestion and samples were carefully mixed at room temperature. The necessary amount of trypsin was added ( $\sim 1$ molecule of trypsin to 50 molecule of substrate) to the samples immediately before placing them in a heating block. The samples were digested at $20,35,45,50,52,54,56,58,60,68$ and $70^{\circ} \mathrm{C}$ for $30 \mathrm{~min}$.

Membrane protein digestion using DIET method. Membrane preparations were digested without denaturation or alkylation. In each experiment, approximately $250 \mu \mathrm{g}$ of membrane proteins were used in a final volume of $50 \mu \mathrm{L}$. Each sample contained $10 \mathrm{mM}$ Tris $\mathrm{HCl}$ buffer, $\mathrm{pH}$ 8.5, $5 \mathrm{mM}$ dithiothreitol, $0.1 \%$ (w/v) SDS and $10 \mathrm{mM} \mathrm{CaCl}_{2}$ with $\mathrm{NaCl}(200 \mathrm{mM})$ or without. Trypsin to substrate ratio was 1:50. The samples were incubated at $52^{\circ} \mathrm{C}$ for $30 \mathrm{~min}$.

Detection of SDS using Hayashi test. Hayashi test was done as previously described ${ }^{16}$. Briefly, an SDS-containing sample $(335 \mu \mathrm{L})$ was mixed with a solution containing $7 \mu \mathrm{L}$ of $0.5 \%$ methylene blue and $170 \mu \mathrm{L}$ of sodium phosphate $(0.7 \mathrm{M}, \mathrm{pH}$ 7.2). Chloroform (1 mL) was added to this solution and vortexed immediately. The solution was left for $5 \mathrm{~min}$ to form phase partitioning. A small volume $(100 \mu \mathrm{L})$ of the lower part was used to measure absorbance at $665 \mathrm{~nm}$. Absorbance of $0.1 \%(\mathrm{w} / \mathrm{v})$ SDS solution (without $\mathrm{NaCl}$ and $\mathrm{CaCl}_{2}$ ) was defined as $100 \%$.

Detection of SDS in solutions containing $\mathrm{NaCl}$. $\mathrm{NaCl}$ was added to the $0.1 \%$ of SDS solution containing $10 \mathrm{mM} \mathrm{CaCl}_{2}$. The final concentrations of $\mathrm{NaCl}$ was $0,25,50$, $75,100,150$ and $200 \mathrm{mM}$. Triplicates of the solutions were incubated for $30 \mathrm{~min}$ at $22^{\circ} \mathrm{C}$ and $52^{\circ} \mathrm{C}$ and centrifuged immediately at $15000 \times \mathrm{g}$ for $3 \mathrm{~min}$. The supernatants were used for Hayashi test without delay as described above.

Removal of SDS after protein digestion. For removal of SDS digested mixtures were frozen at $-20^{\circ} \mathrm{C}$, defrosted and centrifuged at $15000 \times \mathrm{g}$ for $10 \mathrm{~min}$. The pellets were discarded and the absence of SDS in supernatants was confirmed by Hayashi test. SDS-free supernatants were used for mass spectrometry and SDS PAGE analyses.

\section{Digestion of membrane preparations using acid labile detergent Rapigest.} Membrane proteins were digested following manufacturer's protocol. Briefly, protein sample $(250 \mu \mathrm{g}$ in $50 \mu \mathrm{L})$ containing $0.1 \%(\mathrm{w} / \mathrm{v})$ Rapigest and $5 \mathrm{mM}$ DTT was incubated for $30 \mathrm{~min}$ at $60^{\circ} \mathrm{C}$. The sample was cooled down and $15 \mathrm{mM}$ iodoacetamide was added. This solution was incubated in the dark for $30 \mathrm{~min}$. Trypsin was added in the ratio of 1 molecule of enzyme to 50 molecules of the substrate. The mixture was 
incubated at $37^{\circ} \mathrm{C}$ overnight. After overnight incubation Rapigest was cleaved using TFA ( $\mathrm{pH} 2)$ and the pellet was removed by centrifugation. Supernatant was used for mass spectrometry and SDS PAGE analyses.

Preparation of membrane peptides using conventional protein digestion method. Membrane preparations were re-suspended in $8 \mathrm{M}$ Urea/50 mM triethylammonium bicarbonate, reduced with dithiothreitol and alkylated with iodoacetamide. Samples were then diluted $8 x$ with $50 \mathrm{mM}$ triethylammonium bicarbonate, trypsin was added to make a protein/trypsin ratio of 50/1 and incubated at $37^{\circ} \mathrm{C}$ overnight. Peptides were desalted using a SepPak Light cartridge (Waters Corporation) and dried to the volume of $20 \mu \mathrm{L}$.

Mass-spectrometry analysis and data processing. Proteomics was carried out by the University of Leicester Proteomics Facility (PNACL, University of Leicester). LCMS/MS was carried out using a RSLCnano HPLC system (Dionex, UK) and LTQOrbitrap-Velos mass spectrometer (Thermo Scientific). Samples were loaded at high flow rate onto a reverse-phase trap column $(0.3 \mathrm{~mm}$ i.d. $\times 1 \mathrm{~mm})$, containing $5 \mu \mathrm{m} \mathrm{C}_{18}$ $300 \AA$ Acclaim PepMap media (Dionex) maintained at a temperature of $37^{\circ} \mathrm{C}$. The loading buffer contained $0.1 \%$ formic acid / $0.05 \%$ trifluoroacetic acid $/ 2 \%$ acetonitrile. Peptides were eluted from the trap column at a flow rate of $0.3 \mu \mathrm{l} / \mathrm{min}$ and through a reverse-phase capillary column (75 $\mu$ m i.d. x $250 \mathrm{~mm})$ containing Symmetry $\mathrm{C}_{18} 100$ $\AA$ media (Waters, UK) that was manufactured in-house using a high pressure packing device (Proxeon Biosystems, Denmark). The output from the column was sprayed directly into the nanospray ion source of the LTQ-Orbitrap-Velos mass spectrometer. The LTQ-Orbitrap-Velos mass spectrometer was set to acquire a 1 microscan FTMS scan event at 60000 resolution over the $\mathrm{m} / \mathrm{z}$ range 300-2 $000 \mathrm{Da}$ in positive ion mode. The maximum injection time for MS was $500 \mathrm{~ms}$ and the AGC target setting was $1 \mathrm{e}^{6}$. Accurate calibration of the FTMS scan was achieved using a background ion lock mass for $\mathrm{C}_{6} \mathrm{H}_{10} \mathrm{O}_{14} \mathrm{~S}_{3}(401.922718 \mathrm{Da})$. Subsequently up to 10 data dependent HCD MS/MS were triggered from the FTMS scan. The isolation width was $2.0 \mathrm{Da}$, normalized collision energy 42.5. Dynamic exclusion was enabled. The maximum injection time for MS/MS was 250 ms and the AGC target setting was $5 e^{4}$.

The raw data file obtained from each LC-MS/MS acquisition was processed using Proteome Discoverer (version 1.4, Thermo Scientific), searching each file in turn using Mascot $^{17}$ (version 2.2.04, Matrix Science Ltd.) against the L. monocytogenes reference proteome downloaded from UniProtKB ${ }^{18}$ (Proteome ID: UP000000817). The 
peptide tolerance was set to $10 \mathrm{ppm}$ and the MS/MS tolerance was set to $0.05 \mathrm{Da}$. Fixed modifications were set as carbamidomethyl $(C)$ with variable modification of oxidation (M). Trypsin was selected as the enzyme and up to 3 missed cleavages were allowed. A decoy database search was performed.

The output from Proteome Discoverer was further processed using Scaffold $Q+S^{19}$ (version 4.0.5, Proteome Software). Upon import, the data was searched using X!Tandem ${ }^{20}$ (The Global Proteome Machine Organization). PeptideProphet ${ }^{21}$ and ProteinProphet $^{22}$ (Institute for Systems Biology) probability thresholds of $95 \%$ were calculated from the decoy searches and Scaffold was used to calculate an improved 95\% peptide and protein probability threshold based on the data from the two different search algorithms

SDS-PAGE Analysis of Digested Proteins. A solution (15 $\mu \mathrm{L})$ containing ovalbumin and trypsin was placed on ice immediately after completion of digestion. Laemmli sample buffer $(5 \mu \mathrm{L})$ was added to the samples and incubated at $95^{\circ} \mathrm{C}$ for $5 \mathrm{~min}$. These protein digests were analysed on $12 \%$ SERVA gels using GeneFlow PAGE instrument.

\section{Results}

SDS solubility in the presence of calcium ions depends on temperature. SDS is a mass spectrometry incompatible detergent and its removal is critical for further analysis. Figure 1 shows results of Hayashi test performed on SDS-containing samples. At room temperature SDS precipitated in the presence of $\mathrm{CaCl}_{2}$, however, elevation of temperature to $52^{\circ} \mathrm{C}$ completely abolished precipitation of SDS even in the presence of $50 \mathrm{mM} \mathrm{NaCl}$. (Figure 1). Therefore, cooling down the mixture to room temperature can be used for removal of SDS from trypsin-digested samples.

Establishment of protocol for protein digestion by trypsin at elevated temperature. Ovalbumin is resistant to proteinase cleavage and represents an ideal model substrate for development of digestion methods. We hypothesised that elevated temperature may improve ovalbumin digestion by trypsin and used a range of temperatures for validation experiments. We also evaluated buffers with different $\mathrm{pH}$. Digestion buffers contained $200 \mathrm{mM} \mathrm{NaCl}, 5 \mathrm{mM}$ DTT and $20 \mathrm{mM}$ Tris- $\mathrm{HCl}$, at pH 7.0, 7.5, 8.0 and 8.5. Efficiency of ovalbumin digestion was assessed using polyacrylamide gel electrophoresis and quantitation of the protein bands was done using ImageJ 
software (https://imagej.nih.gov/ij/). This protein was not digested at the different range of temperatures tested $\left(20\right.$ to $\left.75^{\circ} \mathrm{C}\right)$. Previously it has been reported that addition of solvents promoted cleavage of proteins, ${ }^{23}$ however application of various concentrations of acetonitrile, dimethyl sulfoxide and methanol did not improve digestion of ovalbumin in our experiments. Similarly, supplementation of digestion buffer with detergents such as Triton $\times 100$, Tween 20 and 80 and Brij series had no effect on ovalbumin digestion. Interestingly, addition of sodium dodecyl sulphate (SDS) to the buffer dramatically improved digestion of ovalbumin at elevated temperature, giving the best results at $50-52^{\circ} \mathrm{C}$ (Figure $2 \mathrm{~A}, \mathrm{~B}$ ). Densitometry analysis showed that $50 \%$ of protein remained undigested, indicating potential inactivation of trypsin at high temperature. Addition of $\mathrm{Ca}^{2+}$ ions to the buffer stabilised trypsin. As shown in Figures $2 \mathrm{C}$ and $\mathrm{D}$ ovalbumin could be completely digested at $50-56^{\circ} \mathrm{C}$ in the presence of calcium chloride. Buffer was also critical for efficient digestion; trypsin had poor activity at lower $\mathrm{pH}$ but increasing the $\mathrm{pH}$ of the buffer had a positive effect on digestion. Figures $2 \mathrm{C}$ and $\mathrm{D}$ demonstrate that the maximum efficiency of digestion was achieved at $52-56^{\circ} \mathrm{C}$ in buffer with $\mathrm{pH}$ 8.5. Further increase of temperature gradually decreased the efficiency of digestion, suggesting that at temperatures exceeding $58^{\circ} \mathrm{C}$ trypsin was inactivated and failed to digest ovalbumin.

\section{Validation of DIET for detection of membane proteins from $L$. monocytogenes.}

Membrane fractions of $L$. monocytogenes were prepared in three biological replicates, and each replicate was split in two parts where efficiency of two different methods of digestion was compared against each other. As shown in Figure 3 the total number of proteins identified using the conventional method of digestion was 304 with 51 uniquely identified proteins. The amount of proteins identified by DIET was 401 in total, with 148 uniquely identified proteins (Figure 3).

Statistical analysis of the membrane proteins identified by two methods. The volcano plot in Figure 4 shows the results of differentially identified proteins based on fold change versus t-test probability. The plot was obtained by comparing proteins derived from the traditional method with proteins derived from DIET. Figure 4 shows data inferred from the experiment with samples (three biological replicates) treated with the traditional method and samples (three biological replicates) digested with DIET, with 401 proteins identified in total and quantified by 2 or more peptides. Proteins showing high $p$-values are marked as green squares enclosed in a red rounded square (Significantly Different), where the $p<0.05$ is set as a threshold. Here, 
above this threshold only proteins identified with the negative values of fold change (ratio of traditional method/DIET) can be observed. This clearly shows a high efficiency of the DIET method. Proteins showing high p-values and not identified by the traditional method of digestion are marked as green triangles (Significant Outlier). Once again, the Significant Outlier is the set of proteins that can only be identified by DIET.

DIET method can be used for efficient digestion and identification of membrane/cell wall and transmembrane proteins. Proteins shown with the high $p$ value (Figure 4) assigned as Significantly Different and Significant Outlier were analysed using Uniprot database. The results are given in the Tables S1 and S2. In the Table S1 set of proteins (21) are shown. Those were identified by DIET only and no peptide was identified at all by the traditional method of digestion (Significant Outlier). Here we see 17 transmembrane or membrane/cell wall associated proteins, three uncharacterised and only one cytoplasmic protein (30S ribosomal protein S21). In Table S2 a total 38 proteins are shown, 26 of them are transmembrane or membrane/cell wall associated proteins and 5 uncharacterised proteins. Only 7 proteins in this table are cytosolic proteins (4 ribosomal, 1 DNA polymerase and 2 likely cytoplasmic proteins). These results show that the membrane proteins enrichment was successful and identification of such proteins mostly depend on digestion procedure.

Digestion of membrane proteins using acid labile detergent. Rapigest is one of the most popular mass spectrometry and trypsin compatible surfactants which has been recently developed for improvement of membrane protein digestion. We therefore used Rapigest for digestion of $L$. monocytogenes membrane preparations. As Figure 5 shows 948 proteins could be identified using the Rapigest method compared with 528 proteins identified by the DIET method.

\section{Discussion}

All the biological substances are enclosed in the membrane, and it allows life forms on Earth to exist as we know them today. Proteins associated with or embedded in the membrane form the machinery that enable cells to sense and interact with the world, transport compounds and ions in and out, build cell walls and do many other essential tasks. Symbiotic and pathogenic bacteria have evolved numerous strategies to interact with their hosts, and hosts in response evolved their own systems to interact 
with bacteria. ${ }^{1,2}$ The host-microbe interactions involve protein-protein recognition, yet our current understanding of these interactions is limited. The role of the membrane proteins in host-pathogen interaction has been extensively investigated for decades. Significance of the subject forced proteomics researchers to develop new and efficient methods for membrane protein study. Overall, mass spectrometry has become the key technology in protein research and isolation and effective digestion of membrane proteins are the essential part for such research.

Previously we have shown that cytoplasmic proteins can be digested by simple incubation at high temperature without chemical denaturation, reduction and alkylation of the proteins. ${ }^{7}$ In the current project we used a proteolysis resistant protein ovalbumin as a model of difficult to digest protein. We found that many chemicals (acetonitrile, dimethyl sulfoxide, methanol, ethanol and detergents of Triton, Tween and Brij series) have a limited effect on denaturation and digestion of ovalbumin at high temperature. However, strong ionic detergent SDS dramatically improved digestion of this protein. In Figure 1 we showed that protein digestion is $\mathrm{pH}$ dependent, $\mathrm{pH} 8.5$ being ideal. Gradually increasing the temperature resulted in partially digested protein (at 50 and $52^{\circ} \mathrm{C}$ ). However, further increase of temperature prevented digestion of protein. Ascribing this effect to the denaturation of trypsin itself at high temperature we attempted to stabilise it. Sipos and Merkel shown in 1970s that calcium stabilise trypsin at higher temperature. ${ }^{24}$ However, there are complications in using calcium in combination with detergents and certain buffers. The most common buffer used in proteomics is ammonium bicarbonate and it is known that bicarbonate $\left(\mathrm{HCO}_{3}^{-}\right)$ions react with $\mathrm{Ca}^{2+}$ ions, and form insoluble carbonic acid calcium salt $\left(\mathrm{CaCO}_{3}\right)$. Therefore, we recommend avoiding the use of carbonate buffers for this type of experiments. Another challenge is a calcium dodecyl sulphate precipitation. ${ }^{25}$ Calcium ions are precipitated in SDS and removed from the solution. This problem can be solved by addition of sodium chloride, as $\mathrm{NaCl}$ increases tolerance toward calcium ${ }^{26}$ preventing formation of calcium dodecyl sulphate and precipitation. Thus, we digested ovalbumin with trypsin in a solution that contained $\mathrm{SDS}, \mathrm{CaCl}_{2}$ and $\mathrm{NaCl}$. As shown in Figure $1 \mathrm{~B}$ the maximum efficiency of digestion occurred at $52-56^{\circ} \mathrm{C}$. Densitometry evaluation ${ }^{27}$ shows that ovalbumin is fully digested at $52^{\circ} \mathrm{C}$, with $56^{\circ} \mathrm{C}$ showing slightly lower productivity. Results of this experiment suggest that the most effective temperature range for treatment is $52-54^{\circ} \mathrm{C}$. Previously we have shown that 
incubation at elevated temperature for a long period of time causes decrease in peptide recovery, ${ }^{7}$ therefore it is desirable to incubate for 30 minutes only.

The pilot experiments with the membrane proteins were carried out with the partially purified membrane fractions of $L$. monocytogenes. The results show superiority of the DIET over the traditional method of digestion. Thus, the total amount of proteins identified using DIET was 401, while that of the traditional method was only 304 (Figure 3). The sequence coverage of individual proteins was much higher in case of DIET.

Next, bacterial membrane fractions were isolated from a large volume of culture in triplicate so that statistical analysis could be carried out. The membrane fractions were split into two sets, one of which was treated using DIET and the second set was treated by the traditional method of digestion. Statistical analysis of the membrane proteins showed that proteins identified by DIET are predominantly membrane and transmembrane proteins. Figure 4 shows the result of quantification by 2 or more peptides as it gives the highest probability of identification. In Figure 4 we show the volcano plot where the $\mathrm{x}$-axis is a fold change of peptides identified by traditional method of digestion compared to that of DIET and the statistical significance is on the $y$-axis, that is - $\log 10$ of the $p$-value. Here proteins identified with the larger magnitude fold changes in DIET are farther to the left, while highly significant changes appear higher on the $y$-axis. We see here that peptides assigned with the high $p$-value are on the left part of the plot only. Those are the sets of peptides identified by DIET, designated as Significantly Different. A set of peptides showing high p-values and not identified by the traditional method of digestion are marked as Significant Outlier.

Proteins assigned as Significantly Different and Significant Outlier on Figure 4 were analysed on Uniprot database. In Table S1 there are 21 proteins in total, 17 of them are transmembrane or membrane/cell wall associated proteins and three uncharacterised proteins. Here only one cytoplasmic protein is present, $30 \mathrm{~S}$ ribosomal protein S21. Those proteins were identified by DIET only and no peptide was identified at all by the traditional method of digestion (Significant Outlier in Figure 4). Next, in Table S2 we show 38 proteins with 26 transmembrane or membrane/cell wall associated proteins and 5 uncharacterised proteins. Only 7 proteins here are cytosolic proteins (4 ribosomal, 1 DNA polymerase and 2 likely cytoplasmic proteins). Proteins in this table are identified with high mascot scores and with larger protein coverage by DIET, while a traditional method of digestion failed to identify them with high 
confidence. As we can see here the sets of proteins identified by DIET, but not identified by the traditional method are dominated by membrane/cell wall and transmembrane proteins.

However, comparison of the DIET method with the Rapigest method showed that further optimisation is required to improve protein digestion in the presence of SDS. Rapigest is one of the most potent surfactants used for the mass spectrometry analysis of membrane proteins ${ }^{28}$, nevertheless the Rapigest method involves several steps which have to be carefully followed for successful digestion. Moreover, the method requires expensive reagents and might not be suitable for express validation of samples. The DIET method is simple, cheap and easy to use and as such it can be adapted for a high throughput analysis of membrane proteins. Protein digestion using this method takes only $30 \mathrm{~min}$ and does not require any pre or post treatment of the substrates. Finally, the concept of trypsin stabilisation can widen a list of surfactants that can be used to improve digestion of "difficult" proteins.

\section{Notes}

The authors declare no competing financial interest

\section{ACKNOWLEDGMENTS}

The project was supported by the UK Biotechnology and Biological Sciences Research Council grants BB/H008586/1 and BB/K000330/1 (to G.V.M.), MRC-DTG (to J.L.). Ministry of Education in Saudi Arabia. Riyadh, Saudi Arabia.

\section{Reference List}

(1) Schweppe D. K.; Harding C,; Chavez J. D.; Wu X.; Ramage E.; Singh P. K.; Manoil C.; Bruce J. E. Host-microbe protein interactions during bacterial infection. Chem Biol. 2015, 22, 1521-1530.

(2) Jiggins F. M.; Hurst G. D. D.; Yang Z. Host-symbiont conflicts: positive selection on an outer membrane protein of parasitic but not mutualistic Rickettsiaceae Mol. Biol. Evol. 2002, 19, 1341-1349.

(3) Moore S. M.; Hess S. M.; Jorgenson J. W. Extraction, enrichment, solubilization, and digestion techniques for membrane proteomics. J. Proteome Res. 2016, 15, 1243-1252

(4) Aebersold R.; Mann M. Mass spectrometry-based proteomics. Nature 2003, 422, 198-207. 
(5) Domon B.; Aebersold R. Mass spectrometry and protein analysis. Science 2006, 312, 212-217.

(6) Medzihradszky K. F. Peptide sequence analysis. Methods Enzymol. 2005, 405, 50-65.

(7) Turapov O.; Mukamolova G.V.; Bottrill A.R.; Pangburn M.K. Digestion of native proteins for proteomics using a thermocycler. Anal. Chem. 2008, 80, 6093-6099.

(8) Park Z.Y.; Russell D.H. Thermal denaturation: a useful technique in peptide mass mapping. Anal. Chem. 2000, 72, 2667-2670.

(9) Pramanik B. N.; Mirza U.A.; Ing Y.H.; Liu Y.H.; Bartner P.L.; Weber P.C.; Bose A. K. Microwave-enhanced enzyme reaction for protein mapping by mass spectrometry: A new approach to protein digestion in minutes. Protein Sci. 2002, 11, 2676-2687.

(10) Olszowy P. P.; Burns A.; Ciborowskia P. S. Pressure-assisted sample preparation for proteomic analysis. Anal. Biochem. 2013, 438, 67-72.

(11) López-Ferrer D.; Capelo J. L.; Vázquez J. Ultra fast trypsin digestion of proteins by high intensity focused ultrasound. J. Proteome Res. 2005, 4, 1569-1574.

(12) Tsiatsiani L.; Heck A. J. Proteomics beyond trypsin. FEBS J. 2015, 282, $2612-$ 2626

(13) Walsh, K. A. Trypsinogens and trypsins of various species. Meth. Enzymol. 1970, 19, 41-63.

(14) Turapov O.; Loraine J.; Jenkins C. H.; Barthe P.; McFeely D.; Forti F.; Ghisotti D.; Hesek D.; Lee M.; Bottrill A. R.; Vollmer W.; Mobashery S.; Cohen-Gonsaud M.; Mukamolova G. V. The external PASTA domain of the essential serine/threonine protein kinase PknB regulates mycobacterial growth. Open Biol. 2015, 5, 150025.

(15) Turapov O.; Forti F.; Kadhim B.; Ghisotti D.; Sassine J.; Straatman-Iwanowska A.; Bottrill A. R.; Moynihan P. J.; Wallis R.; Barthe P.; Cohen-Gonsaud M.; Ajuh P.; Vollmer W.; Mukamolova G. V. Two faces of CwIM, an essential PknB substrate, in Mycobacterium tuberculosis. Cell Rep. 2018, 25, 57-67

(16) Hayashi K. A rapid determination of sodium dodecyl sulfate with methylene blue. Analytical Biochemistry. 1975, 67. 503-506

(17) Perkins D. N.; Pappin D. J. C.; Creasy D. M.; Cottrell J. S. Probability-based protein identification by searching sequence databases using mass spectrometry data. Electrophoresis 1999, 20, 3551-3567.

(18) UniProt Consortium. The Universal Protein Resource (UniProt) in 2010. Nucleic Acids Res. 2010, 38, D142-158. 
(19) Searle B. C. Scaffold: a bioinformatic tool for validating MS/MS-based proteomic studies. Proteomics 2010, 1265-1269.

(20) Craig R.; Beavis R. C. TANDEM: matching proteins with tandem mass spectra. Bioinformatics 2004, 20, 1466-1467.

(21) Keller A.; Nesvizhskii A. I.; Kolker E.; Aebersold R. Empirical statistical model to estimate the accuracy of peptide identifications made by MS/MS and database search. Anal. Chem. 2002, 74, 5383-5392.

(22) Nesvizhskii, A. I., Keller, A., Kolker, E. \& Aebersold, R. A statistical model for identifying proteins by tandem mass spectrometry. Anal. Chem. 2003, 75, 46464658.

(23) Russell W. K.; Park Z-Y.; Russell D. H. Proteolysis in mixed organic-aqueous solvent systems: applications for peptide mass mapping using mass spectrometry. Anal. Chem. 2001, 73, 2682-2685.

(24) Sipos T.; Merkel J. R. Effect of calcium ions on the activity, heat stability, and structure of trypsin. Biochemistry 1970, 9, 2766-2775.

(25) Maneedaeng A.; Flood A. E.; Haller K. J.; Scamehorn J. F. Temperature dependence of the solubility product of calcium dodecyl sulfate and modeling of the phase boundary. BIWIC 2007, $135-142$.

(26) Baviere M.; Bazin B.; Aude R. Interactions of surfactants with polyvalent cations in solution and at the mineral-water interface. Journal of Colloid and Interface Science 1983, 92, 580-583.

(27) Gassmann M.; Grenacher B.; Rohde B.; Vogel J. Quantifying Western blots: pitfalls of densitometry. Electrophoresis 2009, 30, 1845-1855.

(28) Vit O, Petrak J.. Integral membrane proteins in proteomics. How to break open the black box? J Proteomics. 2017. 153, 8-20.) 


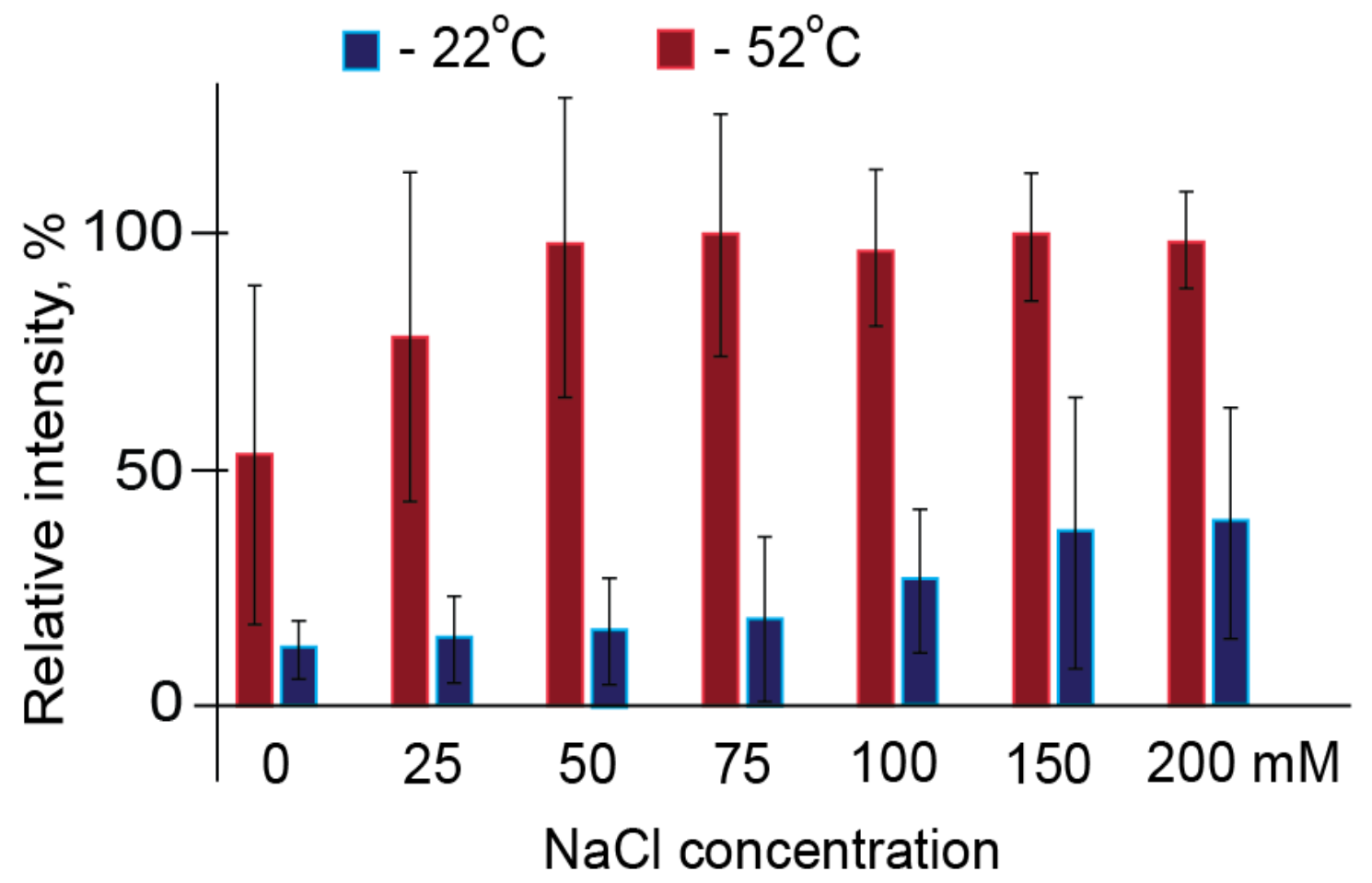

Figure 1. Measurement of SDS using Hayashi test. Solutions containing $0.1 \%$ SDS, $10 \mathrm{mM} \mathrm{CaCl} 2$ and various concentration of $\mathrm{NaCl}$ was incubated for 30 min at $22^{\circ} \mathrm{C}$ (dark blue bars) and $52^{\circ} \mathrm{C}$ (red bars). SDS precipitates were removed by centrifugation, and soluble part was used for Hayashi test. A small volume (100 $\mu \mathrm{L})$ of the organic phase was used to measure absorbance at $665 \mathrm{~nm}$. Absorbance of $0.1 \%$ (w/v) SDS solution (without $\mathrm{NaCl}$ and $\mathrm{CaCl}_{2}$ ) was defined as $100 \%$. 

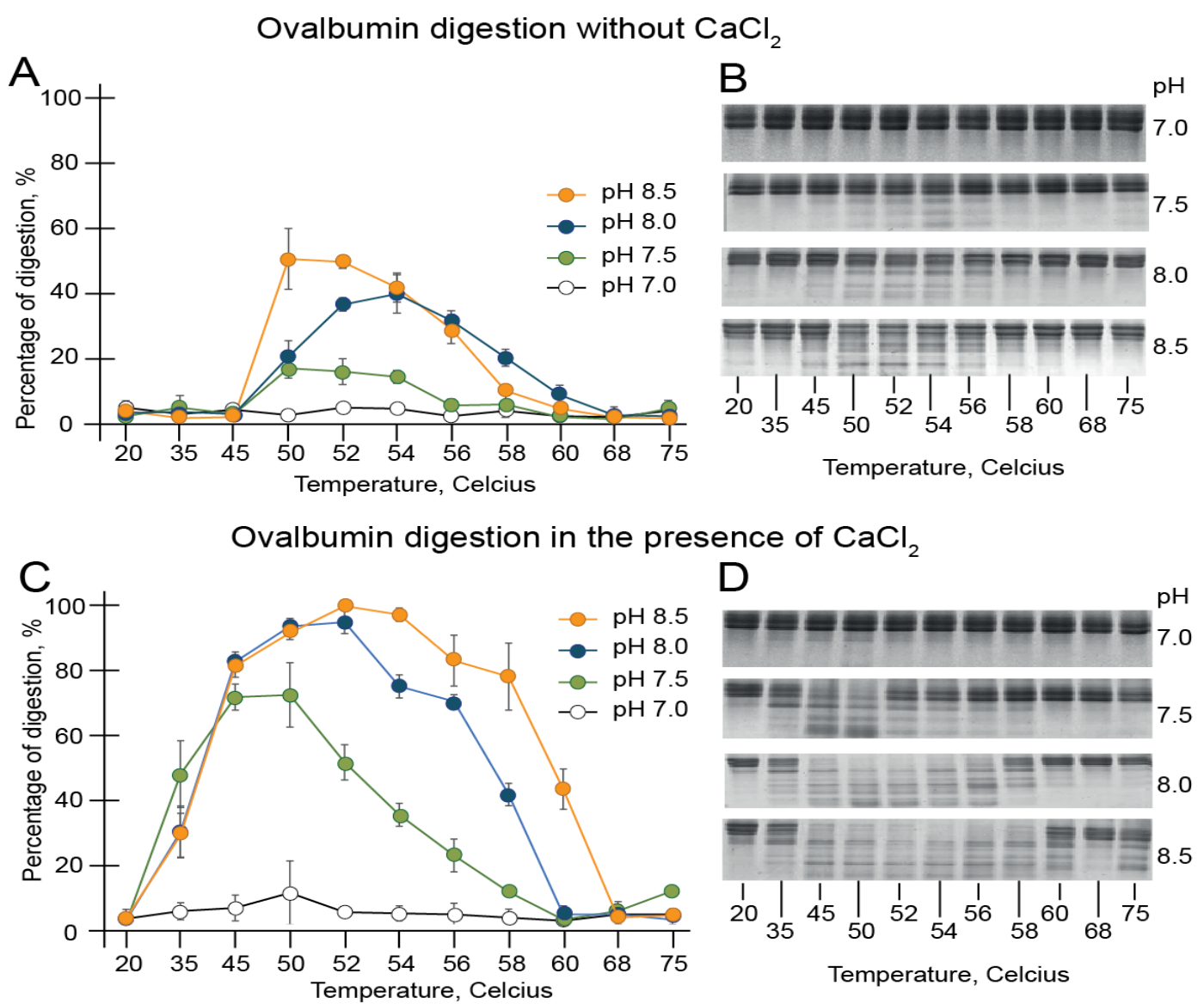

Figure 2. Digestion of ovalbumin by trypsin. Ovalbumin was digested in the presence of SDS without calcium ions. Protein was digested under different $\mathrm{pH}$ at indicated temperatures. SDS PAGE gel bands were analysed and quantified using ImageJ software as described by Gassmann M. et al. ${ }^{27}$ (B) Ovalbumin was digested at $\mathrm{pH} 7.0$, 7.5, 8.0 and 8.5 in the presence of SDS without calcium ions. Protein was digested for $30 \mathrm{~min}$ at indicated temperatures and the reaction was stopped by adding Laemmli sample buffer. The protein digests were analysed on 12\% SERVA gels using GeneFlow PAGE instrument. (C) Ovalbumin was digested in the presence of both SDS and calcium ions. Protein was digested under different $\mathrm{pH}$ at indicated temperatures. SDS PAGE gel bands were analysed and quantified using ImageJ software. (D) Ovalbumin was digested at pH 7.0, 7.5, 8.0 and 8.5 in the presence of both SDS and calcium ions. Protein was digested for $30 \mathrm{~min}$ at indicated temperatures and the digested protein samples were analysed using SDS PAGE. Experiments were performed at least three times, error bars show a standard deviation 


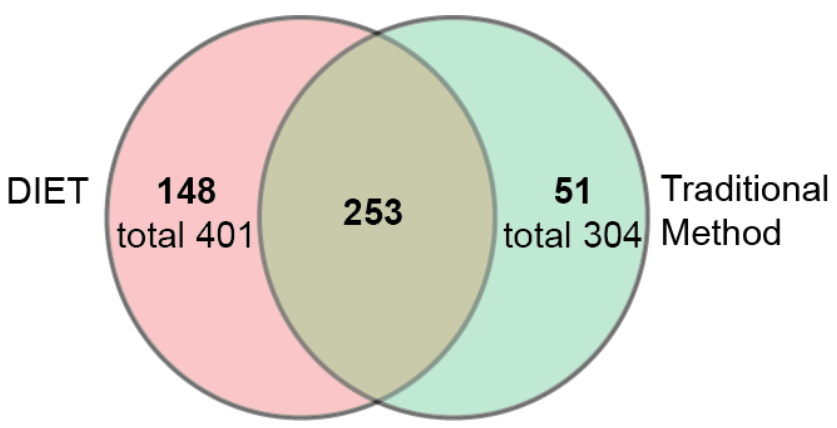

Figure 3. Investigation of membrane proteins from L. monocytogenes. Membrane fractions of L. monocytogenes were prepared and split in two parts. One part of the sample was digested using a traditional method of digestion and another one was digested using DIET method. Digested proteins were analysed by mass spectrometry. A total number of proteins identified using the conventional method of digestion was 304 while 401 proteins were identified by DIET. The amount of uniquely identified proteins by DIET was 148, while that of traditional method was 51 . 
Volcano Plot (T-Test, $p<0.00551)$

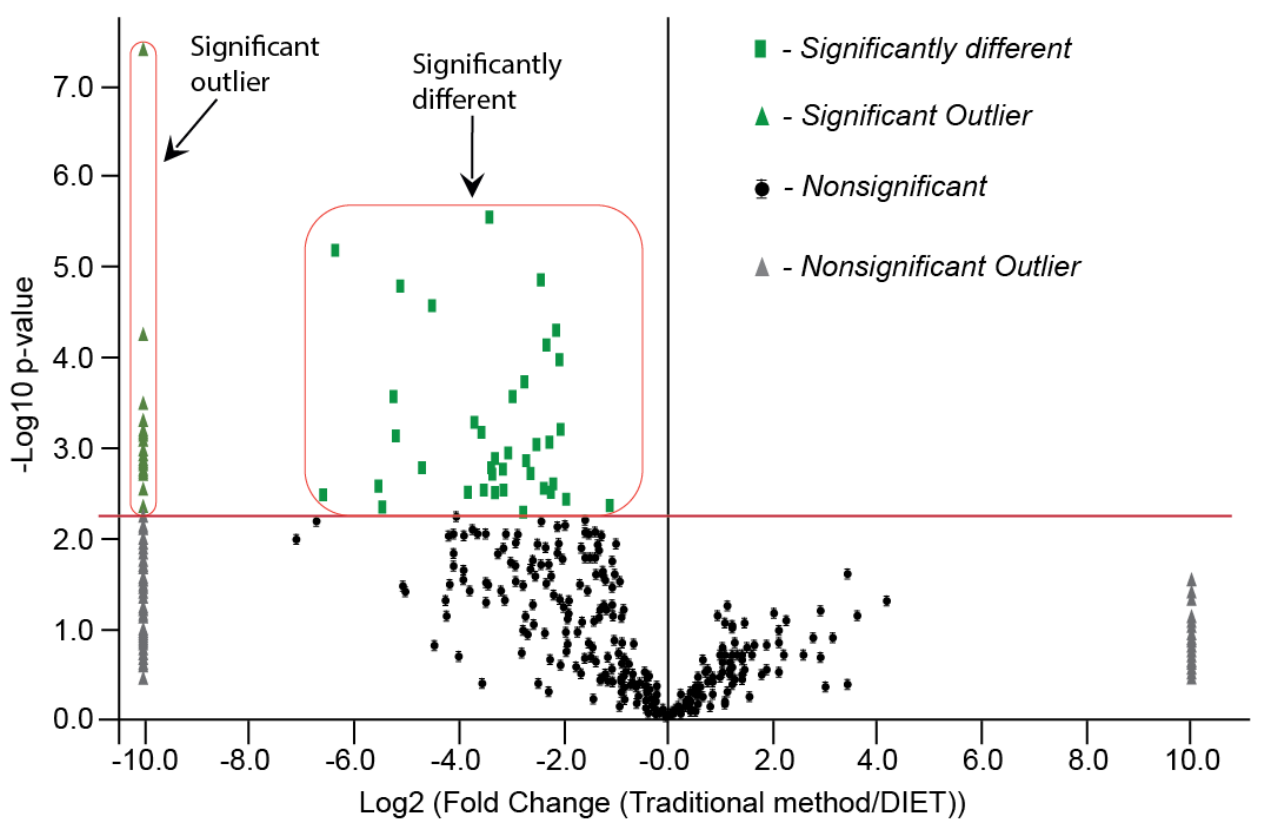

Figure 4. Statistical analysis of the membrane proteins identified by traditional method of digestion and DIET. The volcano plot shows the results of differentially identified proteins based on fold change versus t-test probability. Proteins with high $p$-values are shown in green squares enclosed in a red rounded square (Significantly Different). Here only proteins identified with the negative values of fold change (ratio of traditional method/DIET) are shown. Proteins showing high p-values and not identified by the traditional method of digestion are marked as green triangles (Significant Outlier) 


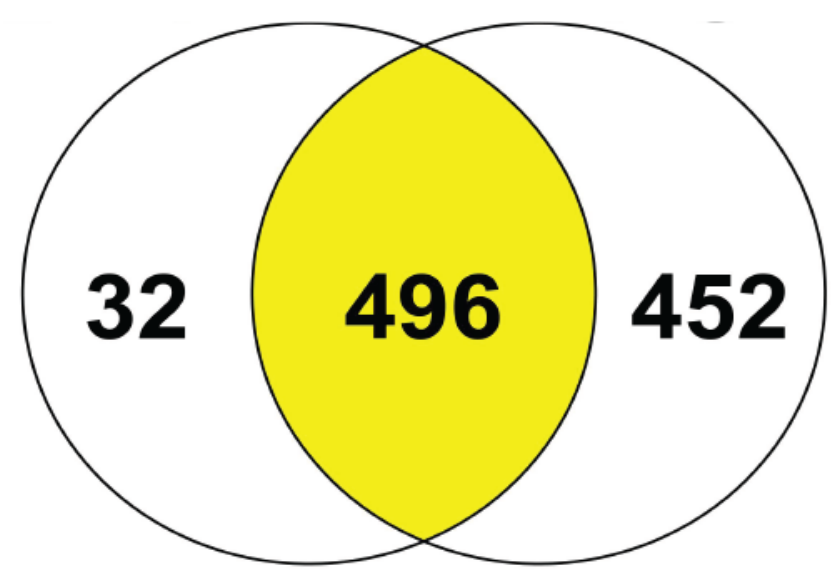

Figure 5. Digestion of membrane proteins using Rapigest and DIET method. Acid labile detergent Rapigest was used for digestion of $L$. monocytogenes membrane proteins. Using this method 948 proteins were identified. Following it DIET method was used to digest and analyse membrane proteins. This method identified 528 proteins. 


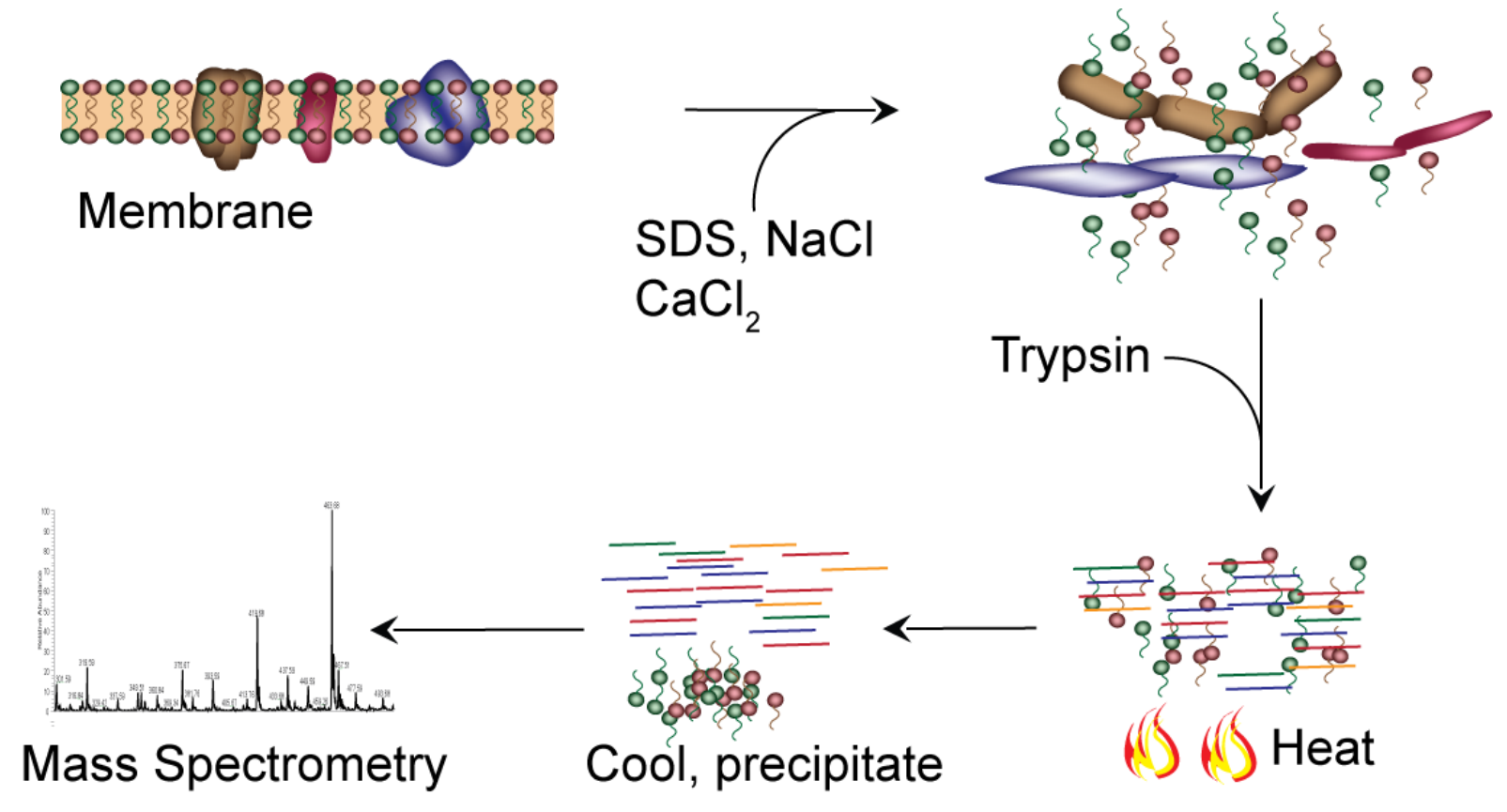

For TOC only 